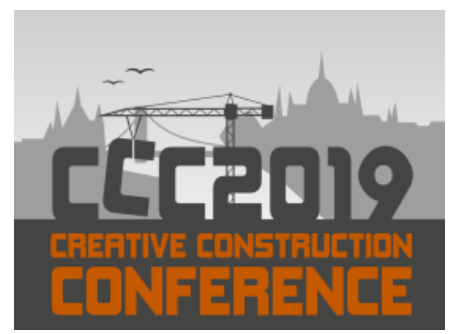

Available online at 2019.creative-construction-conference.com/proceedings/

CCC 2019

Proceedings of the Creative Construction Conference (2019) 068

Edited by: Miroslaw J. Skibniewski \& Miklos Hajdu

https://doi.org/10.3311/CCC2019-068

Creative Construction Conference 2019, CCC 2019, 29 June - 2 July 2019, Budapest, Hungary

\title{
Traceability for built assets: proposed framework for a Digital Record
}

\author{
Richard Watson ${ }^{\mathrm{a} *}$, Mohamad Kassemª ${ }^{\mathrm{a}}$ Jennifer $\mathrm{Li}^{\mathrm{a}}$ \\ ${ }^{a}$ Faculty of Engineering and Environment, Northumbria University, Newcastle NE1 8ST, UK
}

\begin{abstract}
In May 2018, the UK Government published an independent review of building regulations and fire safety in response to the tragic fire at Grenfell Tower. The Hackitt Review identified the need for traceability; a 'golden thread' preserving critical information about design intent and the as-constructed building in a proposed Digital Record (DR). This study proposes a framework for a DR for traceability of all built assets, new and existing. Three structured workshops including four working groups were held with industry practitioners and academics to collaboratively establish definitions of traceability and a DR. The key requirements of the DR were identified through development of 63 use cases. Building on traceability systems research in other industries, a framework for traceability of built assets was developed and analysed with industry. The framework, containing both information chains, supply chains and unique identification of traceable items, is outlined in this paper and its key components are discussed along with identification of areas for further research.
\end{abstract}

(C) 2019 The Authors. Published by Budapest University of Technology and Economics \& Diamond Congress Ltd.

Peer-review under responsibility of the scientific committee of the Creative Construction Conference 2019.

Keywords: digital record; traceability; information chain, supply chain, construction industry; Hackitt Review.

\section{Introduction}

In June 2017, a tragic event resulted in the death of 71 people when a publicly-owned, high rise residential building in London, United Kingdom (UK) caught fire. Subsequent investigations identified systemic failures [1] as contributory factors in the tragedy. This prompted a review of building and fire safety commissioned by the UK Government - the Hackitt Review [2] identified the construction industry as slow to adopt traceability and quality assurance techniques in comparison to other industries and recommended a Digital Record (DR) for higher risk residential buildings (HRRBs) to ensure stakeholders have access to accurate, up-to-date information throughout the building lifecycle. Three reasons why traceability is required in the construction industry emerged from the Hackitt Review: i) to provide confidence/assurance and the ability to check that 'things are as they should be', the correct product has been installed correctly, complies with the relevant standards and has been maintained appropriately; ii) to ensure the required information is available to facilitate action in the event of non-compliance; and iii) to provide the ability to access all information about a product, offering wider potential benefits such as a more effective product recall system, better quality control, improved procurement and support for continuous development and learning from experience [2].

Traceability of built assets is challenged by both the particular nature of the construction industry and built assets. Some of the key challenges include: very long project and asset lifecycles exceeding 60 years; the complex information

*Corresponding author: Richard Watson, email: Richard.Watson@northumbria.ac.uk 
Watson et al. / Proceedings of the Creative Construction Conference (2019) 068

https://doi.org/10.3311/CCC2019-068

chain from requirements and design, through construction to in-use (including design and ownership changes, product data, and adaptations); the varied nature of procurement processes adopted; difficulty in identification and tagging of products; and varying granularity of products and information.

The aim of this study is to establish a framework for a DR for the construction industry as set out in the Hackitt Review. It is achieved by: developing working definitions for traceability and a DR validated by stakeholders; establishing the components required for a traceability system (drawing on existing research and application in other industries); and testing and validation of these proposals with stakeholders. The scope of this study includes all types of built assets, new and existing across all stages of the asset lifecycle whether for new build, renovation or retrofit. Increased traceability in construction is proposed to lead to improvements in accountability and compliance with regulations and the ability to support product recall, resulting in a safer built environment for its occupants.

Section 2 discusses traceability in the construction industry; section 3 presents the workshops conducted for this study and highlights the results; section 4 describes the proposed framework and the results from the workshops; and section 5 provides discussion, conclusions and next steps for the research.

\section{Traceability in construction}

While no formal definition for traceability is provided in the Hackitt Review, a definition is required in the context of the construction industry to: i) support shared understanding of objectives; ii) guide development of proposed solutions; and iii) provide a test to evaluate any proposed solution. There is currently no comprehensive, industry-wide scheme to support traceability in the construction industry in the UK. A number of publications discuss aspects of traceability in construction, however, most lack a formal definition. Katenbayeva et al., [3] simply state it "is the ability to follow information related to a product through its supply chain" (p. 3) providing a number of uses: quality and safety, minimising scandals that damage company reputations, improved supply chains, and enhancing trust. Kamara et al., [4] state "client requirements have to be presented in a manner that will facilitate: (...) [t]he traceability of design decisions to original requirements throughout the life-cycle of the facility" (p. 17). Hao et al., [5] link traceability to client requirements and initial building design where the number of changes throughout a construction project can be reduced when accurate client requirements are captured at the outset and effective traceability is embedded thereafter.

The food industry has a more advanced system in place for traceability and is very effective in holding the industry to the highest standards of food safety and quality assurance. Building on previous ISO definitions, Olsen and Borit [6] define traceability as "the ability to access any or all information relating to that which is under consideration, throughout its entire lifecycle, by means of recorded identifications" (p. 144). No such definition exists for traceability in construction; establishing one was a key objective of the research in this paper.

There is a body of research investigating the application of technologies such as radio frequency identification (RFID) tags within the construction industry that cite traceability as one of the potential benefits of adoption [7] but much of this work is focused on supply chain efficiency, logistics and inventory management and not directly concerned with addressing many of the issues highlighted in the Hackitt Review.

The Hackitt Review sets out the need for a 'digital record' for buildings that would provide a 'golden thread' of information that preserves design intent, manages changes and ensures stakeholders have access to comprehensive, up-to date information about the building. The relationship between the DR, traceability and industry initiatives already in place, including UK-mandated BIM Level 2, needs to be established requiring a definition of the digital record.

\section{Workshops}

Three workshops with academic and industry practitioners were held to develop and agree a definition of traceability for construction and a definition of a DR and to examine and evaluate these in more detail through the identification of a series of use cases. The first workshop served as a pilot and consisted of four academics with expertise in construction, architecture, the built environment and computer science; the second workshop consisted of nine 
Watson et al. / Proceedings of the Creative Construction Conference (2019) 068

https://doi.org/10.3311/CCC2019-068

participants made up of industry practitioners from across the following professions: software developer, construction information provider, solicitor, designer, architect and home builder; the third had eight participants from manufacturing, legal, software development, fire safety, facilities management, compliance, installation standards and specifications. The workshop participants found the Hackitt Review definition of a DR lacked sufficient detail to form a working definition. The first and second workshops were asked to develop propietary definitions which were then presented, discussed and refined in workshop three. Next, they were asked to consider and identify use cases that would require or benefit from the existence of a robust DR. The use cases were used to further refine and test the definitions developed, scope the requirements for implementation of a DR and to explore potential real-world implementation.

Based on definitions for a DR from the Hackitt Review [2] and those developed during the workshops for this study, the authors propose the following comprehensive definition: A digital record provides traceability through a secure, immutable and auditable electronic record of all required information, actions and decisions taken to assess and achieve compliance of a built asset with relevant standards and regulations at a point in time. It must record stakeholder and compliance requirements, design intent, procurement of materials/components and construction together with the testing, validation and verification processes undertaken, capturing their outcomes in order to provide a complete decision-trail. The record will include physical asset and performance data of all components and support traceability of provenance from raw material state through manufacturing, installation, maintenance and disposal, detailing who did what, when, why, how and to what specification. The digital record must be accurate, traceable, appropriately open, non-proprietary, searchable, and show clear delineations of risk ownership.

An adapted version of the Olsen and Borit [6] definition of traceability was adopted for built asset traceability: The ability to record all required information relating to that which is under consideration, throughout its entire lifecycle, by means of recorded identifications.

These offerings provide idealistic definitions for a DR and traceability and require an authoritative body to define critical aspects such as what the 'required information' is for each type of built asset, recognising they will likely differ between types and at different stages of the asset lifecycle. However, these definitions serve as a point of departure for the industry to consider and improve.

Use cases were identified across the three project lifecycle phases of design, construction and in-use for both new and existing built assets. 63 separate use cases were identified. Some examples of these include: design (e.g. the transfer of initial brief from client to architect; proposed renovations to a building to achieve environmental targets); construction (e.g. tracking changes to the initial design; recording repairs); in-use (e.g. scheduling periodic safety inspection; the sale of an existing building). Three use cases were developed in detail: an energy efficiency project for an existing school; construction of a new HRRB (the focus of the Hackitt Review); and product recall of a gas boiler. The use case development and review activity resulted in: i) a clear understanding that a DR should provide the mechanism for achieving the traceability of information and products required in the industry; ii) an appreciation of how traceability systems already implemented for automotive and food product recall could inform development of a framework for a DR in construction; and iii) definition of a set of use cases that serve to define the scope and requirements of a DR and can be used to test and evaluate proposed solutions.

\section{Proposed framework}

The purpose of a DR is to provide traceability throughout the lifecycle of a built asset [2]. The Hackitt Review recommends the adoption of a traceability system and learning from other sectors where traceability is more advanced. Traceability in manufacturing and food sectors is primarily concerned with identifying the source (e.g farm), input materials and supporting full backward and forward tracking, to determine the location and life history in the supply chain of a product $[8,9]$. For a built asset, such a system would provide the ability to answer questions such as, "Where did this product come from, what is it made of and does it meet the required standards?" (backwards traceability); and, "Who sold all the products from this batch and where are they now?" (forwards traceability). The Hackitt Review also highlights the importance of recording the original "design intent" so that any subsequent changes can be identified. A DR framework for built assets must therefore support traceability of requirements and corresponding design 
Watson et al. / Proceedings of the Creative Construction Conference (2019) 068 https://doi.org/10.3311/CCC2019-068

solutions. Sectors such as safety-critical software applications require traceability across requirements, proposed solutions, verification and validation [10]. A holistic framework is proposed encompassing both information and physical chains over the lifecycle of a built asset and the relationships between them as demonstrated in Fig. 1.

Fig. 1. Framework for a digital record in construction

The requirements chain includes requirements set by clients and stakeholders (typically captured in briefing

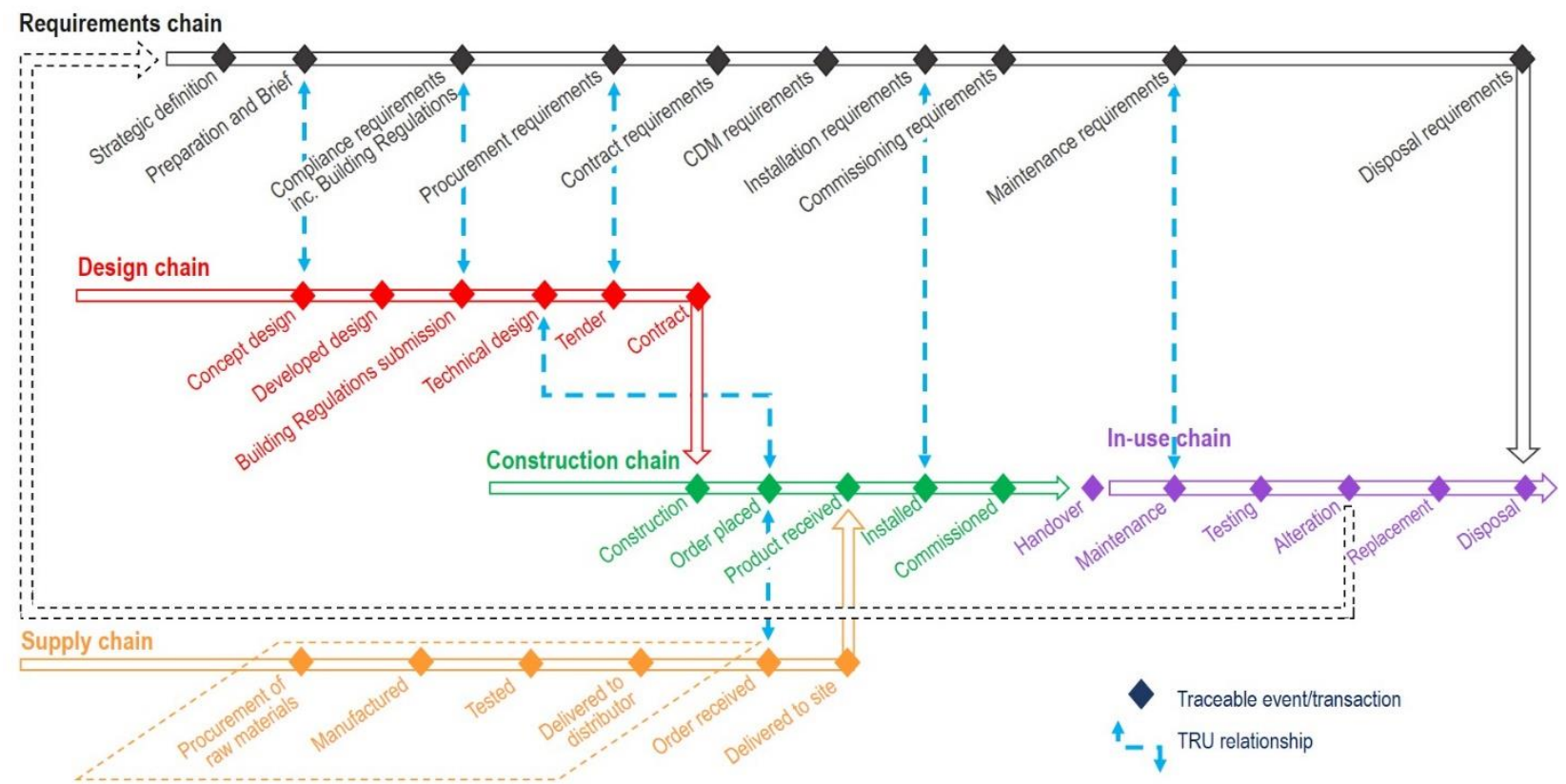

documentation) and requirements set out in legislation (e.g. building regulations, health and safety legislation) and standards. The design chain records the 'design intent' - proposed design solutions in response to requirements. The supply chain includes raw materials, manufacture, testing, sales and distribution of construction products. Depending on the type of product being procured, certain activities will take place either before or after the order is received as indicated by the activities in the dotted box of the supply chain in Fig. 1. The construction chain includes selection of products in response to design solutions, the ordering and delivery of products and materials, installation, sitemanufactured products, commissioning and certification. The in-use chain includes periodic testing and maintenance of the built asset and its constituent parts (either to meet legislative requirements or good practice), repair or replacement of components; adaptation and alteration of the built asset, and changes in ownership, tenants or occupiers. During the in-use chain, alterations will initiate new requirements chains, creating a circular model as indicated by the dotted arrow from Alteration in the in-use chain to Strategic definition in the requirements chain.

Olsen and Borit [6] set out the components of a food traceability system as: a definition of traceability; a definition of a traceable resource unit (TRU) - the item about which traceability information needs to be recorded; and mechanisms for identifying TRUs, documenting transformations (connections between TRUs) and recording the attributes of TRUs. A New Zealand feasibility study [12] defined the requirements of a traceability system aimed at reducing the use of non-conforming products in the construction industry as: unique IDs built on international standards; standard product marking technologies; aggregation of units, including parent-child relationships to establish links between units; data capture supporting access to additional information such as product description and provenance; definition of supply chain events (points in the chain where each shipper and receiver is required to validate units as they change hands); data transfer (how data is transferred and stored and the ability to access data by users). We adopt and extend these components in the definition of the DR framework.

Traceable Resource Unit (TRU) is a well-established general term in literature [6]. In food traceability systems, this is typically applied to trade units (a case, bag, bottle, box), a logistics unit (pallet) or production unit (batch). These are 
Watson et al. / Proceedings of the Creative Construction Conference (2019) 068

https://doi.org/10.3311/CCC2019-068

applicable to the supply-chain for construction products, but for a complete construction traceability approach we extend the concept of a TRU to include traceable 'units' for each of the chains identified. TRUs for requirements and design are non-physical units, which need to be represented digitally to support traceability. TRUs for supply, construction and in-use units will include physical products, components and materials. To support traceability of decision-making and certification, TRUs should also be considered for actors (individuals) and organisations.

The granularity of TRUs will vary from the very small (e.g. an electronic component within a larger piece of equipment) to whole-building scale (e.g. for compliance with energy performance requirements). Building modelling methodologies and classification such as the hierarchy set out in the Uniclass 2015 classification system [13] could be adopted to define the granularity of TRUs for built assets.

Traceability requires recording key relationships between TRUs. The 'composition' relationships must be recorded between the TRUs (e.g. a domestic hot water system and its component products such as radiators, valves and pipes). The 'fulfilment' relationships between requirements, design solutions and installed products must also be recorded along with validation and verification relationships. To support both forward and backward traceability both ancestor and progeny relationships need to be recorded. TRUs must be traceable across organisational boundaries.

TRUs must be uniquely identified, requiring a system that implements identifiers that are unique within the context where they are used [6]. Identifiers must be persistent and usable for the lifecycle of the building and ideally offer a degree of extensibility to support future (as yet unknown) data requirements. Systems such as the GS1 Global Trade Item Number (GTIN) [14] or research into unique product identifiers [15] could be adopted. A system similar to ORCID persistent digital identifiers for academic researchers [16] could be considered as the basis for an identifier system for actors. Requirement and design TRUs will be digital objects, which can support inclusion of unique identifier (UID) codes as attributes (e.g. as a property of an element in the BIM model or specification). TRUs for physical products within the supply, construction and operation chains can be carried using bar codes, QR codes or RFID tags. Consideration needs to be given to where data about the TRU is stored and how it is updated.

As TRUs move through the various chains, information needs to be recorded at key points in time which we term as 'transactions' indicated by diamonds in Fig. 1. Traceable transactions will include: changes in ownership or responsibility (a product is delivered by the supplier to site and the contractor takes ownership, the building is handed over to the client); the fulfilment of a requirement or design (the contractor places an order for a product to fulfil part of the design intent, the design definition progresses from a performance specification to a prescriptive specification); verification and/or validation activity (a product is tested and certified against a standard, a system is commissioned, works are inspected); information transactions (the architect issues design information to the contractor for the purpose of construction); and transformations within the supply and construction chains (components or materials are combined in the creation of a product, products are incorporated into the building). These transactions need to be uniquely identifiable within the DR, therefore, require UIDs. Metadata about the transaction needs to be recorded, including purpose, date, time and the parties involved. The precise data to be recorded will depend on the transaction type. At each transaction, key information must be recorded about the TRUs included within that transaction. These attributes will differ depending on the type of TRU and the transaction and can potentially be defined from information contained in BIM information exchanges. The NBS BIM toolkit [17] offers a potential starting point to define TRUs and required attributes, particularly for the design chain.

Storage of the traceability data outlined above needs to support: access by project stakeholders; trust (that the data is accurate and has not been altered); security (preventing unauthorised access to sensitive data); privacy (protecting personal data); and long-term access for the lifecycle of the building. The Hackitt Review recommends that the DR be "open and non-proprietary and with proportionate security controls" ([2], p.60). These requirements suggest distributed ledger technologies (DLT) may offer suitable plaftom to host the DR and will be explored further in future research. 
Watson et al. / Proceedings of the Creative Construction Conference (2019) 068

https://doi.org/10.3311/CCC2019-068

\section{Discussion and conclusions}

The Hackitt Review identified significant failings in UK processes for compliance, quality and accountability in the construction and alteration of HRRBs. The review recommended a digital standard of record keeping (a digital record), supporting a 'golden thread' of information (traceability), but did not give explicit and implementable definitions for either. Other industries, such as food, manufacturing and automotive have implemented supply-chain traceability systems to improve product quality and safety and support product recall. The need for traceability of requirements in sectors such as safety-critical software is also well-established [10]. Traceability research in the construction industry has focused on client requriements [4] and the application of RFID tagging to support construction supply chain management and logistics, tracking and tracing of materials, site quality control, inventory management and lifecycle/facilities management [7]. Based on the definition of construction traceabilty proposed here, we suggest that implementation of a comprehensive DR to support full traceability of built assets must cover both the information supply chain (requirements and design solutions) and product supply chain (manufacturing, construction and in-use) and the critical relationships between them. The components and requirements for traceability systems set out in Olsen and Borit [6] and Dowdell [12], have provided a basis for the development of the DR framework set out in this paper. The framework and accompanying definitions for construction traceability and DR have been evaluated in a series of workshops with industry experts against a set of use cases.

Further work identified by the authors and through the workshops includes: additional industry input and review to validate the proposed framework; detailed specification of the TRU attributes to be recorded (mandatory and best practice); development of a comprehensive list of transactions across all information and supply chains; identification of a suitable UID and carrier system; identification of the existing processes and information systems that could be incorporated into a DR. There is substantial research to be undertaken to define the technical implementation (platform) of a DR, including the technical approach and architecture, ownership and sharing of data, and definition of how existing systems, data records and processes (e.g. BIM) are integrated. Finally, consideration needs to be given to the strategy by which industry adoption will be secured, the degree to which this is mandated (as in the food industry), the need for any regulatory bodies and the balance between complexity, cost and ease of implementation and adoption.

\section{References}

[1] T. Symonds, C. Ellison, Grenfell Tower cladding failed to meet standard, BBC News. (2018). https://www.bbc.co.uk/news/uk-43558186 (accessed 14 February 2019).

[2] J. Hackitt, Building a safer future - Independent Review of Building Regulations and Fire Safety: Interim Report, 2018.

[3] A. Katenbayeva, J. Glass, A. Anvuur, S. Ghumra, Developing a theoretical framework of traceability for sustainability in the construction sector, 12th Corp. Responsib. Reserach Conf. (2016) 0-20.

[4] J.M. Kamara, C.J. Anumba, N.F.O. Evbuomwan, Establishing and processing client requirements—a key aspect of concurrent engineering in construction, Eng. Constr. Archit. Manag. 7 (2000) 15-28. https://doi.org/10.1108/eb021129

[5] Q. Hao, W. Shen, J. Neelamkavil, J.R. Thomas, Change management in construction projects, in: Proc. CIB W78 25th Int. Conf. Inf. Technol. Improv. Manag. Constr. Proj. Through IT Adopation, Santiago, Chile, 2008: pp. 387-396.

[6] P. Olsen, M. Borit, The components of a food traceability system, Trends Food Sci. Technol. 77 (2018) 143-149. https://doi.org/10.1016/j.tifs.2018.05.004

[7] Y. El Ghazali, É. Lefebvre, L.A. Lefebvre, The potential of RFID as an enabler of knowledge management and collaboration for the procurement cycle in the construction industry, J. Technol. Manag. Innov. 7 (2012) 81-102. https://doi.org/ 10.4067/S0718-27242012000400007

[8] L.U. Opara, Traceability in agriculture and food supply chain: A review of basic concepts, technological implications, and future prospects, WFL Publ. Sci. Technol. 1 (2003) 101-106.

[9] A. Bechini, M.G.C.A. Cimino, F. Marcelloni, A. Tomasi, Patterns and technologies for enabling supply chain traceability through collaborative e-business, Inf. Softw. Technol. 50 (2008) 342-359. https://doi.org/10.1016/j.infsof.2007.02.017

[10]H. Dubois, M.A. Peraldi-Frati, F. Lakhal, A model for requirements traceability in a heterogeneous model-based design process: Application to automotive embedded systems, Proc. IEEE Int. Conf. Eng. Complex Comput. Syst. ICECCS. (2010) 233-242. https://doi.org/ 10.1109/ICECCS.2010.2

[11]RIBA, RIBA Plan of Work 2013, (2013). https://www.ribaplanofwork.com/Default.aspx (accessed 1 November 2018).

[12]D. Dowdell, I. Page, M. Curtis, Electronic traceability of New Zealand construction products: Feasibility and opportunities, Judgeford, New Zealand, 2017.

[13]NBS, Uniclass 2015, (2019). https://www.thenbs.com/our-tools/uniclass-2015 (accessed 14 April 2019).

[14]GS1, Global Trade Item Number (GTIN), (2019). https://www.gs1.org/standards/id-keys/gtin (accessed 14 April 2019).

[15] Riba Enterprises Ltd, Persistent Digital Identifiers for Construction Products, UK Res. Innov. (2019). https://gtr.ukri.org/projects?ref=102057 (accessed 14 April 2019).

[16] ORCID, ORCID, (2019). https://orcid.org/ (accessed 14 April 2019).

[17]NBS, NBS BIM Toolkit, (2019). https://toolkit.thenbs.com/ (accessed 14 April 2019). 